\title{
The Influence of Organisational Climate on Knowledge Management: A Literature Review
}

\author{
Deepjyoti Choudhury ${ }^{a}$ Prognadipta Das ${ }^{b}$
}

\begin{abstract}
Knowledge is considered to be a strategic resource that helps to leverage the effectiveness of an organisation and is classified into two types: tacit knowledge and explicit knowledge. Tacit knowledge is acquired through long-term experience and cognition while explicit knowledge is a formal knowledge which can be easily shared or transferred. Knowledge management is considered to be an emerging concept in an era of rising global competition that helps to organise and channel the valuable knowledge resource of an organisation and which may therefore ultimately lead to the success of that organisation. However, a cooperative and innovative organisational climate might play a vital role in different aspects of knowledge management with regard to knowledge acquisition, knowledge storage and knowledge sharing. This paper aims to review the literature in the area of knowledge management as well as the influence of organisational climate on knowledge management through the effective flow of tacit knowledge and provide a clear and systematic overview of it. Thus, this study tries to highlight the research gap in the course of reviewing the relevant literature and also attempts to investigate, from the relevant literature, the in-depth relationship, if any, between organisational climate and tacit knowledge management in particular and ultimately knowledge management in general.
\end{abstract}

Keywords: Explicit knowledge; Knowledge; Knowledge Management; Organisational Climate; Tacit Knowledge.

JEL Classification: D23, D83, L15, M10

\section{Introduction}

It is no controversy to say that the entire world has become a global village and in this more competitive climate knowledge plays an indispensable role

a Corresponding author. Department of Business Administration, Assam University, Silchar-788011, Assam, India.Email: choudhurydeepjyoti@gmail.com

b Department of Business Administration, Assam University, Silchar-788011, Assam, India. Email:prognadipta@gmail.com 
in almost every organisation to achieve competitive advantage. Knowledge is often asserted as power and based upon this, it can be said that managing this knowledge in a systematic manner is the ultimate key to power for every organisation. In this ever-changing business world, organisations need to shift from conventional resources to knowledge resources. In the current scenario knowledge is considered to be a strategic organisational resource. Indeed, knowledge has been considered as one of the most highly-valued assets and commodities in every organisation (Bhojaraju, 2005; Hegazy \& Ghorab, 2014). As the domain of business has become more competitive in recent years so to have organisations increasingly needed to face innumerable challenges and contingency situations which accentuate the need to implement knowledge strategies in an effective manner. Every organisation in the era of globalisation needs to understand the fact that change is inevitable and to be competitive in the market, risks and innovations should be undertaken (Bordeianu, 2015). To think about innovative ideas in business processes, one should focus on gathering and communicating knowledge resources as much as possible; only then can an enterprise exploit advantageous opportunities and become efficient in its work process (Nawab et al., 2015). A paradigm shift has taken place with regards to knowledge as a vital resource in enterprises (Jones \& Leonard, 2009). It is believed by some professionals that knowledge management not only generates value but also escalates the performance of organisations. In this respect, the role of knowledge management has recently generated much importance for the survival of enterprises (Omotayo, 2015).

In order to implement knowledge management strategies successfully in an organisation, the knowledge managers need to have an idea about various conditional factors upon which the success of its implementation depends. Amongst those factors, organisational climate is one of the crucial ones (Reyes \& Zapata, 2014; Han, 2018) and they must decide upon the climate which is compatible with selecting the best knowledge management approach. An appropriate organisational climate is one that fosters sharing or dissemination of knowledge among employees in an organisation to a significant extent. Besides this, a suitable organisational climate also has the ability to create an impact upon the employees of an organisation to change their perception, ideas and attitudes in the long run (Long, 2000; Chen \& Lin, 2004) thereby influencing them to adapt the learning environment as well as different strategies for effective organisational performance. Further, 
it may also encourage the members of an organisation to indulge in different activities related to exploiting and disseminating knowledge.

Thus, this particular study is intended to explore the in-depth relationship between organisational climate and knowledge management and contribute to our clear understanding as to whether the presence of certain dimensions of organisational climate can boost the process of tacit knowledge sharing, thereby leading to the better implementation of a knowledge management approach in the organisation. The paper seeks to provide an answer to the following question: How does an organisational climate establish an impact upon knowledge management in an organisation through effective sharing of tacit knowledge?

\section{Review Methodology}

The methodology involved in this study is a narrative literature review, because theoretical discussions of many studies are being collectively undertaken to establish a meaningful link among them, for the purpose of fulfilling the prime objective of this paper. This study made an attempt to search and review the most relevant literature from online databases such as Google Scholar, Science Direct, Springer Link, Jstor and Emerald Insight. The keywords Knowledge, Explicit Knowledge, Tacit Knowledge, Knowledge Management and Organisational Climate were used to search for papers. After following this procedure, certain criteria like title and abstract of the papers were analysed for inclusion or exclusion of papers in the first stage of the screening process. Then, in the second stage entire articles have been read in order to include the most pertinent literatures associated with organisational climate as well as knowledge management. Moreover, to identify the various factors of organisational climate which influences both tacit knowledge sharing as well as knowledge management over time, studies from years 1968-2020 were taken into consideration.

\section{Concepts of Knowledge, Knowledge Management and Organisational Climate}

Knowledge basically comprises data, information and experiences which provide a framework to generate further information and experience. Davenport \& Prusak (1998), defined knowledge as "a fluid mix of 
framed experience, values, contextual information and expert insight that provides a framework for evaluating and incorporating new experiences and information. It originates and is applied in the minds of knower". ${ }^{1}$ Knowledge is basically subdivided into two categories: Tacit Knowledge and Explicit Knowledge. The knowledge which can be easily articulated is termed as "explicit knowledge" while "tacit knowledge" is something which is difficult to articulate and hence cannot be transferred easily (Polanyi, 1966). Explicit knowledge is a formal kind of knowledge that can be expressed precisely in the form of data, manuals, textbooks or certain scientific formulae (Ajayi \& Opeke, 2017). Tacit knowledge is that type of knowledge which is imbibed in the minds, behaviour and perception of employees in any organisation (Sthulman, 2012).

Various researchers have defined knowledge management in different ways at different times. Knowledge management is defined as an approach towards the systematic, explicit and deliberate creation, renewal and application of knowledge in order to augment the knowledge-related efficacy of organisations (Wiig, 1997). Knowledge management is a specified methodical process for attaining, organising and sharing both tacit as well as explicit knowledge so that employees can use the knowledge for effective work processes in an organisation (Alavi \& Leidner, 1999). Carlsson (2001), defined knowledge management as a process of identifying, managing and enhancing both individual as well as collective knowledge to support the enterprise in sustaining market competition. According to Karlsen \& Gottschalk (2004), knowledge management is defined as a method in which the process of generating, capturing, sharing and understanding knowledge in an organisation is improved. According to American Productivity \& Quality Center (2007), knowledge management implies the strategies and processes adopted to identify, obtain and leverage knowledge to support the organisation to compete. The sharing of knowledge, which forms an integral part of knowledge management processes is interlinked with other processes like the creation, transfer, learning, distribution and collaboration of knowledge resources (Foss et al. 2010; Fayard \& Metiu, 2014).

The concept of organisational climate was first introduced by Kurt Lewin who termed it a psychological atmosphere. With time, the concept of organisational climate attained many meanings. It is perceived to be a set of attributes prevalent in a working environment which directly or indirectly influences the behaviour of employees. Organisational climate implies the 
shared values, beliefs and workplace atmospheres that create a significant impact upon the behaviour of employees (Long, 2000). To any individual member within an organisation, climate primarily refers to the overall pattern of organisational activities (Jaw and Liu, 2003). Organisational climate include values, trust, motivation, teamwork, an innovative culture, collaboration, decision making processes, creativeness. (Moffett et al., 2003; Syed-Ikhsan \& Rowland, 2004; Anantatmula \& Kanungo, 2006). Besides this, other dimensions of organisational climate comprise training and development, transformation and diversity, job satisfaction, leadership, employee wellness, communication, performance management, remuneration and reward, work environment and the image of the organisation (Castro \& Martins, 2010).

\section{Relationship between Organisational Climate and Knowledge Management}

An organisational climate creates an impact upon knowledge management and it is evident that when an organisation has more innovative and cooperative climate, the interaction among employees becomes favourable and thus the rate of knowledge sharing improves (Chen \& Huang, 2007). Abzari \& Abbasi (2011) conducted research in which they studied the impact of organisational climate in the components of planned behaviour theory and opined that an appropriate organisational climate should be prevalent for knowledge sharing in an organisation. Suitable organisational environment are needed for the sharing and management of knowledge among the employees to create a synergic impact between knowledge of both employees as well as outside environments and the knowledge thus produced is rich in quality (Kohansal et al., 2013). Organisational climate serves as a critical prognosticator in the sphere of knowledge management and has a positive impact upon sharing and the application of knowledge (Lashari et al., 2016). According to Razzaq et al. (2017), the organisational climate positively and significantly influences the knowledge management practices among the professionals in healthcare organisations.

As far as tacit and explicit knowledge is concerned, tacit knowledge is regarded as valuable for an organisation and thus individuals are not willing to share it easily (Osterloh \& Frey, 2000) but try to withhold it for individual gain and for attaining competitive edge in the market (Huie, Cassaberry \& 
Rivera, 2020). As opined by Polanyi (1966), tacit knowledge is something inherent to an individual and is difficult to express, however it forms the basis for explicit knowledge. However, unlike tacit, explicit knowledge can be shared easily through books, manuals, video clips, databases, expert systems and formal training (Pangil \& Nasurddin, 2013). According to Huie, Cassaberry \& Rivera (2020), organisations require the tacit form of knowledge which is generally embedded in the minds of people in order to make a strong organisational knowledge base and improve the performance level. Through the sharing of valuable tacit knowledge, which is intangible in character and an asset of knowledge management, individuals can greatly contribute to the improvement of organisational performance (Reychav \& Weisberg, 2009). Indeed, effective management and sharing of tacit knowledge, that forms a strategic factor of knowledge management, plays a key role in the success of organisations as well as sustainability in the global economy (Mohajan, 2016). Peroune (2007), also opined that in the practical world, much of the knowledge is tacit in nature. Thus, it needs to be communicated across the organisation for effective implementation of a knowledge management approach. However, the sharing of tacit knowledge is highly dependent upon social interaction among individuals (Nonaka, 1994; Yang \& Farn, 2006). Moreover, cooperative organisational climates lead to a boost in the trust level among employees and with a higher level of internal trust, employees have the tendency to share more of their tacit knowledge for the betterment of the organisation (Leana and Buren, 1999; Szulanski et al., 2004; Zaheer, Bill McEvily \& Perrone, 1998; Lin, 2007). According to Ekore (2014), both explicit as well as tacit knowledge possess no value until and unless it is being deployed for enhancing organisational efficiency and thus successful knowledge transfer within the organisation is essential.

There are extensive studies which have attempted to examine the relation between knowledge management and organisational culture as compared to the inter-relationship between knowledge management and organisational climate (Gupta \& Govindarajan, 2000; McDermott \& O’Dell, 2001; Park et al., 2004; Al-Alawi et al., 2007; Suppiah \& Sandhu, 2011). Moreover, on the basis of above-mentioned literatures, it is quite evident that tacit knowledge, which is a key element of knowledge management is difficult to share and members of an organisation often feel reluctant to disseminate their tacit knowledge with others. Also, it is not possible for 
an individual who has expertise in certain exclusive knowledge or skills to articulate each and every aspect of it and here arises the importance of sharing this tacit knowledge through interaction or communication (Tsoukas, 2001; Coulson-Thomas, 2004). So, there must be some triggering organisational factors which leverage the employees' tendency to share the same. According to Fainshmidt \& Frazier (2016), it has been asserted that organisational climate has a key role to play in efficacious and easy flows of knowledge throughout an organisation. However, we need to analyse further which are the various factors that are responsible to create and improve any organisation's climate for successful knowledge management to take place and how they do so. Thus, amongst various organisational factors; here comes the mention of certain variables of organisational climate and how it can trigger the sharing of tacit knowledge thereby ascertaining a positive influence upon the knowledge management process. Hence, a clear research gap exists, which indicates that we need to undertake further research to find out the precise relationship between organisational climate and knowledge management. The study will particularly delve into how organisational climate can positively influence knowledge management practices, while considering the different factors or variables of organisational climate impacting especially upon tacit knowledge sharing in particular and knowledge management as a whole.

\section{Factors of Organisational Climate: Leveraging Tacit Knowledge Sharing}

From the different surveyed literature, Table 1 presents an overview of certain factors informing organisational climate which contributes to tacit knowledge sharing in an organisation.

Thus, it clearly indicates that factors of organisational climate which are being identified from various literatures namely teamwork, trust, leadership, organisational structure, the reward system, employee interactions and motivation facilitates tacit knowledge sharing as well as effective knowledge management procedures in an organisation. 
Table 1: Factors of organisational climate identified and its contribution in tacit knowledge sharing.

\begin{tabular}{l} 
Factors (Sources) \\
\hline 1) Teamwork \\
(Grant, 1997); (Davenport \& Prusak, 1998); \\
(Grant, 2001); (Noordin et al., 2010); (Castro \\
\& Martins, 2010); (Gonzalez \& Martins, 2014); \\
(Khanghahi, 2014); (Obrenovic, Obrenovic \& \\
Hudaykulov, 2015); (Li \& Mahadevan, 2017).
\end{tabular}

\section{2) Trust}

(Koys \& Decottis, 1991); (Hinds \& Pfeffer, 2003); (Mooradian et al., 2006); (Choi et al., 2008); (Barachini, 2009); (Castro \& Martins, 2010); (Casimir et al., 2012); (Hudcova, 2014); (Nesic \& Lalic, 2016); (Roodbari et al., 2016).

\section{3) Leadership}

(Nahapiet \& Ghoshal, 1998); (Goh, 2002); (Noordin et al., 2010); (Castro \& Martins, 2010); (Micic, 2015); (Nair \& Munusami, 2019).

\section{4) Motivation}

(Noordin et al., 2010); (Roodbari et al., 2016); (Razmerita et al., 2016).

5) Social relationships/employee interactions (Moran \& Volwein, 1992); (Marquardt, 1996); (Osterloh \& Frey, 2000); (Li \& Mahadevan, 2017).

\section{6) Reward}

(Litwin \& Stringer, 1968); (Davenport \& Prusak, 1998); (Paroutis \& Al Saleh, 2009); (Razmerita et al., 2009); (Castro \& Martins, 2010); (Oye et al., 2011); (Li \& Mahadevan, 2017); (Huie, Cassaberry \& Rivera, 2020).

\section{7) Organisational design/structure}

(Litwin \& Stringer, 1968); (Chen et al., 2010); (Noordin et al., 2010); (Pandey \& Dutta, 2013).
- Trust is considered as one of the salient dimensions of organisational climate.

- Leadership as a factor forms the basis of organisational climate in different studies.

- It is evident that motivation has been considered as one of the factors of organisational climate.

- Relationships or interactions have been identified as dimension of organisational climate in various studies.

- Various authors regarded reward as one of the key variables of organisational climate.

- Certain studies mentioned organisational design or structure as a prime factor of organisational climate.
Factors' Contribution in Tacit Knowledge Sharing

- Encourages collaboration and sharing of tacit knowledge resulting in better organisational performance.

- Supports different phases of the knowledge management process.

- An atmosphere of trust is very essential to facilitate tacit knowledge sharing.

- Efficient leadership attributes have the ability to foster tacit knowledge sharing in an organisation.

- Motivation develops tacit knowledge sharing among the employees and as such an organisation should make an effort to increase the motivation of employees.

- Transfer of tacit knowledge involves healthy social networks or interactions.

- Suitable reward systems motivate the employees to share their tacit knowledge thereby enhancing the knowledge management process.

- Organisational design or structure helps to steer tacit knowledge thus enabling a smooth knowledge management process. 
Hence, from the above discussions we can ascertain that organisational climate has an impact upon knowledge management and their relationship can be exemplified in Figures 1 and 2:

Figure 1: Factors of organisational climate influencing tacit knowledge sharing.

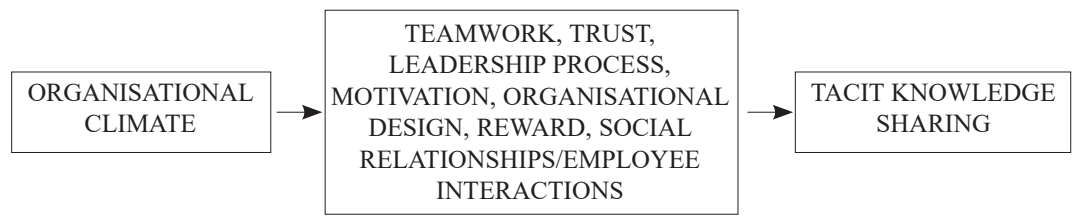

Source: Author.

Figure 2: Relationship of organisational climate with tacit knowledge sharing and knowledge management.

\begin{tabular}{c|c|}
\hline $\begin{array}{c}\text { ORGANISATIONAL } \\
\text { CLIMATE }\end{array}$ & $\rightarrow \begin{array}{c}\text { TACIT KNOWLEDGE } \\
\text { SHARING }\end{array} \rightarrow \begin{array}{c}\text { KNOWLEDGE } \\
\text { MANAGEMENT }\end{array}$ \\
\hline
\end{tabular}

Source: Author.

\section{Conclusion and Future Research Scope}

This particular study gives an insight inro the relation between organisational climate and knowledge management. From Figure 1 and Figure 2, it is clearly understood that the presence of certain factors of organisational climate leads to the sharing of tacit knowledge in an organisation which ultimately creates an impact upon knowledge management because tacitknowledge sharing forms an integral part of the knowledge management process. The narrative review of available literatures has made an attempt to provide evidence of a positive relationship between tacit knowledge sharing with that of organisational climate. Moreover, the study also supports the view that the presence of suitable organisational climatic factors leads to the enhancement of knowledge sharing and thus successful knowledge management is possible in an organisation. It's clearly understood that knowledge management by itself cannot be a success until and unless there 
are some other organisational factors which can help spread knowledge sharing, especially tacit knowledge. This study indeed contributes to our understanding of how various factors of organisational climate can positively influence the implementation as well as the survival of knowledge management in an enterprise. However, there may be other possible avenues on which further research on knowledge management can embark on, taking into account more diversified factors of organisational climate or culture to generalise the relationship between them.

The paper is confined to one of the organisational factors namely organisational climate that triggers effective knowledge management implementation neglecting other probable organisational variables. Due to the paucity of time and available resources, the focus of this study has been limited to only a single aspect, that is to find out whether there is an in-depth relationship between organisational climate and knowledge management through leveraging tacit knowledge sharing. The current study has not considered each variable of organisational climate, rather it has selected a few of them as per convenience. Moreover, the review of earlier studies is not based on any particular time frame. Whatever studies which seemed to be considerably relevant by analysing the titles, abstracts and entire papers were taken into consideration to generalise the findings.

\section{References}

Abzari, M. \& Abbasi, R. (2011). Investigating impact of organizational climate on intention to knowledge sharing behaviour by using theory of planned behaviour (TPB). Interdisciplinary Journal of Contemporary Research in Business, 2(12), 121-134.

Ajayi, B. T. \& Opeke, R. O. (2017). Challenges of incorporating knowledge sharing for effective performance in insurance company. International Journal of Applied Technologies in Library and Information Management, 3(2), 54-66. http://www.jatlim.org.

Alavi, M. \& Leidner, D. (1999). Knowledge management systems: issues, challenges and benefits. Communication of the AIS, 1(7), 1-37. DOI: 10.17705/1CAIS.00107.

Al-Alawi, A. L., Al-Marzoogi, N. Y. \& Mohammed, Y. F. (2007). Organisational culture and knowledge sharing: critical success factors. Journal of Knowledge Management, 11(2), 22-42. DOI:10.1108/13673270710738898. 
Anantatmula, V. \& Kanungo, S. (2006). Structuring the underlying relations among the knowledge management outcomes. Journal of Knowledge Management, 10(4), 25-42. http://dblp.uni-trier.de/db/journals/jkm/ jkm10.html\#AnantatmulaK06.

Barachini, F. (2009). Cultural and social issues for knowledge sharing. Journal of Knowledge Management, 3(1), 98-110. DOI: 10.1108/13673270910931198.

Bhojaraju, G. (2005). Knowledge management: Why do we need it for corporates. Malaysian Journal of Library \& Information Science, 10(2), 37-50. https://mjlis.um.edu.my/article/view/8488>.

Bordeianu, O. M. (2015). The role of knowledge management and knowledge management strategies within learning organizations. Ecoforum, 4(1(6)), 147-154. http://ecoforumjournal.ro/index.php/eco/ article/download/139/101.

Carlsson, S. A. (2001). Knowledge management in network contexts. $9^{\text {th }}$ European Conference on Information Systems (pp. 616-627). Bled, Slovenia: Global Co-Operation in the New Millenium.

Casimir, G. L. (2012). Knowledge Sharing: Influences of trust, commitment and cost. Journal of Knowledge Management, 16(5), 740-753.

Castro, M. L. \& Martins, N. (2010). The relationship between organizational climate and employee satisfaction in a South African information and technology organization. SA Journal of Industrial Psychology, 36(1), 1-9. DOI: https://doi.org/10.4102/sajip.v36i1.800.

Center, A. P. (2007). Executive Summary of Knowledge Management. American Productivity \& Quality Center. (2007). Executive Summary of Knowledge Management. Houston.

Chen, C.-J. \& Huang, J.-W. (2007). How organizational climate and structure affect knowledge management, the social interaction perspective. International Journal of Information Management, 27(2), 104-118. DOI:10.1016/j.ijinfomgt.2006.11.001.

Chen, C.-J., Huang, J.-W. \& Hsiao, Y.-C. (2010). Knowledge management and innovativeness: The role of organizational climate and structure. International Journal of Manpower, 31(8), 848-870. DOI: https://doi. org/10.1108/01437721011088548.

Chen, C. \& Lin, B. (2004). The effects of environment, knowledge attribute, organizational climate and firm characteristics on knowledge sourcing decisions. $R \& D$ Management, 34(2), 137-146. DOI: https://doi. 
org/10.1111/j.1467-9310.2004.00329.x.

Choi, S. Y., Kang, Y. S. \& Lee, H. (2008). The effects of socio-technical enablers on knowledge sharing: An exploratory examination. Journal of Information Science, 34(5), 742-754. DOI: 10.1177/0165551507087710.

Coulson-Thomas, C. (2004). Transforming the Company, manage change, compete and win. London: Kogan Page.

Davenport, T. H. \& Prusak, L. (1998). Working knowledge: How organizations manage what they know. Harvard Business School Press. DOI: $10.1145 / 348772.348775$.

De Long, D. W. \& Fahey, L. (2000). Diagnosing cultural barriers to knowledge management. The Academy of Management Executive, 14(4), 113-127. DOI: https://doi.org/10.5465/ame.2000.3979820.

Ekore, J. O. (2014). Impact of key organizational factors on knowledge transfer success in multi-national enterprises. Management, 19(2), 3-18.

Fainshmidt, S. \& Frazier, M. L. (2017). What facilitates dynamic capabilities? The role of organizational climate for trust. Long Range Planning, 50(5), 550-566. DOI: https://doi.org/10.1016/j.Irp.2016.05.005.

Fayard, A. L. \& Metiu, A. (2014). The role of writing in distributed collaboration. Organisation Science, 25(5), 1391-413. DOI: 10.1287/ orsc.2013.0893.

Foss, N. J., Husted, K. \& Michailova, S. (2010). Governing knowledge sharing in organisations: Levels of analysis, governance mechanisms and research directions. Journal of Management Studies, 47(3), 455-82. DOI: $10.1111 / \mathrm{j} .1467-6486.2009 .00870 . x$.

Goh, S. C. (2002). Managing effective knowledge transfer: an integrative framework and some practical implications. Journal of Knowledge Management, 6(1), 23-30. DOI: 10.1108/13673270210417664.

Gonzalez, R. D. \& Martins, M. F. (2014). Knowledge management: An analysis from the organizational development. Journal of Technology Management \& Innovation, 9(1), 131-147. DOI: https://doi.org/10.4067/ S0718-27242014000100011.

Grant, A. (2001). Rethinking psychological mindedness: Metacognition, self-reflection and insignt. Behaviour Change, 18(1), 8-17. DOI: https:// doi.org/10.1375/bech.18.1.8.

Grant, R. (1997). The knowledge based view of the firm: Implications for management practice. Long Range Planning, 30(3), 450-4. DOI: https:// doi.org/10.1016/S0024-6301(97)00025-3. 
Gupta, A. \& Govindarajan, V. (2000). Knowledge management's social dimension: Lessons from Nucor Steel. MIT Sloan Management Review, 42(1), 71-80.

Han, S. (2018). The antecedents and dimensionality of knowledge sharing intention: An empirical study of R \& D engineers in high performing IT company. European Journal of Training and Development, 42(1/2), 125-142.

Hegazy, F. M. \& Ghorab, K. E. (2014). The influence of knowledge management on organizational business processes' and employees' benefits. International Journal of Business and Social Science, 5(1), 148-172.

Hinds, P. J. \& Pfeffer, J. (2003). Why organizations don't "know what they know": Cognitive and motivational factors affecting the transfer of expertise. Cambridge: MIT Press.

Hudcova, S. (2014). Tools of internal communication from knowledge transfer perspective. Journal of Competitiveness, 6(4), 50-62. DOI: 10.7441/joc.2014.04.04.

Huie, C. P., Cassaberry, T. \& Rivera, A. K. (2020). The impact of tacit knowledge sharing on job performance. International Journal on Social and Education Sciences, 2(1), 34-40.

Jaw, B. S. \& Liu, W. (2003). Promoting organizational learning and selfrenewal in Taiwanese companies: The role of HRM. Human Resource Management, 42(3), 223-240. DOI: 10.1002/hrm.10082.

Jones, K. \& Leonard, L. N. (2009). From tacit knowledge to organizational knowledge for successful KM. In W.R. King (ed.), Knowledge Management and Organizational Learning (pp. 27-39). Springer Science+Business Media. DOI: 10.1007/978-1-4419-0011-1_3.

Karlsen, J. T. \& Gottschalk, P. (2004). Factors affecting knowledge transfer in IT projects. Engineering Management Journal, 16(1), 3-10. DOI: 10.1080/10429247.2004.11415233.

Khanghahi, M. E. (2014). On the relationship between teamwork and supporting knowledge management. Science Journal of Business and Management, 2(5), 123-130. DOI: 10.11648/j.sjbm.20140205.12.

Kohansal, M. A., Alimoradi, Z. \& Bohloul, S. M. (2013). The impact of knowledge sharing mechanisms on employee performance. International Journal of Business Performance Management, 14(3), 293-306. DOI: 10.1504/IJBPM.2013.054954. 
Koys, D. J. \& DeCotiis, T. A. (1991). Inductive measures of psychological climate. Human Relations, 44(3), 265-85.

Lashari, R. H., Alvi, A. K. \& Farooq, H. M. (2016). The impact of organisational climate on knowledge management in banking sector of Lahore, Pakistan. Science International, 28(5), 81-86.

Leana, C. R. \& Buren, H. J. (1999). Organizational social capital and employment practices. The Academy of Management Review, 24(3), 538-555. DOI: $10.2307 / 259141$.

Lin, C. P. (2007). To share or not to share: Modeling tacit knowledge sharing, its mediators and antecedents. Journal of Business Ethics, 70(4), 411-428. DOI: 10.1007/s10551-006-9119-0.

Li, Y. P. \& Mahadevan, A. (2017). A study on the impact of organisational climate on employee performance in a malaysian consultancy. International Journal of Accounting \& Business Management, 5(1), 1-13. DOI: 24924/ijabm/2017.04/v5.iss1/1.13.

Litwin, G. H. \& Stringer, R. A. (1968). Motivation and Organizational Climate. Boston: Harvard University Press. DOI: https://doi. org/10.1177/002218567101300314.

Long, D. (2000). Diagnosing cultural barriers to knowledge management. The Academy of Management Executive, 14(4), 113-128. DOI: https:// doi.org/10.5465/ame.2000.3979820.

Marquardt, M. J. (1996). Building the learning organization: A systems approach to quantum improvement. New York: McGraw Hill.

Mcdermott, R. \& O’Dell, C. (2001). Overcoming cultural barriers to sharing knowledge. Journal of Knowledge Management, 5(1), 76-85. DOI: https://doi.org/10.1108/13673270110384428.

Micic, R. (2015). Leadership role in certain phases of knowledge management process. Scientific Review Article, 61(4), 47-56. DOI: 10.5937/ekonomika1504047M.

Moffett, S., McAdam, R. \& Parkinson, S. (2003). An empirical analysis of knowledge management applications. Journal of Knowledge Management, 7(3), 6-26. DOI: 10.1108/13673270310485596.

Mooradian, T., Renzl, B. \& Matzler, K. (2006). Who trusts? Personality, trust and knowledge sharing. Management Learning, 37(4), 523-540. DOI: https://doi.org/10.1177/1350507606073424.

Moran, E. \& Volkwein, J. (1992). The cultural approach to the formation of organizational climate. Human Relations, 45(1), 19-47. DOI: 
10.1177/001872679204500102.

Nahapiet, J. \& Ghoshal, S. (1998). Social capital, intellectual capital and the organizational advantage. The Academy of Management Review, 23(2), 242-266. DOI: $10.2307 / 259373$.

Nair, B. V. \& Munusami, C. (2019). Knowledge management practices: An exploratory study at the Malaysian Higher Education Insitutions. Journal of Research in Innovative Teaching \& Learning. DOI: 10.1108/ JRIT-01-2019-0008.

Nawab, S., Nazir, T., Zahid, M. M. \& Fawad, S. M. (2015). Knowledge management, innovation and organisational performance. International Journal of Knowledge Engineering, 1(1), 43-48. DOI: 10.12691/jbms-4-4-2.

Nesic, A. \& Lalic, D. (2016). The impact of trust on job performance in organisations. Journal of Sustainable Business and Management Solutions in Emerging Economies, 21(81), 27-34. DOI: https://doi. org/10.7595/management.fon.2016.0028.

Nonaka, I. (1994). A dynamic theory of organizational knowledge creation. Organizational Science, 5(1), 14-37. DOI: https://doi.org/10.1287/ orsc.5.1.14.

Noordin, F., Omar, S., Sehan, S. \& Idrus, S. (2010). Organizational climate and its influence on organizational commitment. International Business \& Economics Research Journal, 9(2), 1-9. DOI: https://doi.org/10.19030/ iber.v9i2.516.

Obrenovic, B., Obrenovic, S. \& Hudaykulov, A. (2015). The value of knowledge sharing: Impact of tacit and explicit knowledge sharing on team performance of Scientists. International Journal of Management Science and Business Administration, 1(2), 33-52. DOI: 10.18775/ ijmsba.1849-5664-5419.2014.12.1003.

Omotayo, F. O. (2015). Knowledge management as an important tool in organisational management: A review of literature. Library Philosophy and Practice, 1-23. http://digitalcommons.unl.edu/libphilprac/1238.

Osterloh, M. \& Frey, B. S. (2000). Motivation, knowledge transfer and organizational forms. Organization Science, 11(5), 538-550. DOI: 10.1287/orsc.11.5.538.15204.

Oye, N., Salleh, M. \& Noorminshah, A. (2011). Knowledge sharing in workplace: Motivators and demotivators. International Journal of Managing Information Technology, 3(4), 71-84. DOI: 10.5121/ ijmit.2011.3406. 
Pandey, S. C. \& Dutta, A. (2013). Role of knowledge infrastructure capabilities in knowledge management. Journal of Knowledge Management, 17(3), 435-453. DOI: 10.1504/IJKBD.2015.069457.

Pangil, F. \& Nasurddin, A. M. (2013). Knowledge and the importance of knowledge sharing in organizations. Conference on Business Management Research. Sintok: EDC.

Park, H., Ribiere, V. \& Schulte JR, W. D. (2004). Critical attributes of organisational culture that promote knowledge management technology implementation success. Journal of Knowledge Management, 8(3), 106117. DOI: https://doi.org/10.1108/13673270410541079.

Paroutis, S. \& Al Saleh, A. (2009). Determinants of knowledge sharing using web 2.0 echnologies. Journal of Knowledge Management, 13(4), 52-63. DOI: $10.1108 / 13673270910971824$.

Peroune, D. L. (2007). Tacit knowledge in the workplace: The facilitating role of peer relationships. Journal of European Industrial Training, 31(4), 244-258. DOI: https://doi.org/10.1108/03090590710746414.

Polanyi, M. (1966). The tacit dimension. London: Routledge and Kegan Paul.

Razmerita, L., Kirchner, K. \& Nielsen, P. (2016). What factors influence knowledge sharing in organizations?: A social dilemma perspective of social media communication. Journal of Knowledge Management, 20(6), 1225-1246. DOI: https://doi.org/10.1108/JKM-03-2016-0112.

Razmerita, L., Kirchner, K. \& Sudzina, F. (2009). Personal knowledge management: The role of web 2.0 tools for managing knowledge at individual and organisational levels. Online Information Review, 33(6), 1021-39. DOI: $10.1108 / 14684520911010981$.

Razzaq, K., Rehman, W. u., Dost, M. K. \& Akram, M. W. (2017). Organizational climate and knowledge sharing: A moderating role of cognitive based trust among health care professionals. Journal of Managerial Sciences, XI(3), 443-458.

Reychav, I. \& Weisberg, J. (2009). Going beyond technology: Knowledge sharing as a tool for enhancing customer oriented attitudes. International Journal of Information Management, 29(5), 353-361. DOI: 10.1016/j. ijinfomgt.2008.11.005. 
Reyes, M. M. \& Zapata, D. I. (2014). Relation between organizational climate and its dimensions and knowledge sharing behavior among knowledge workers. International Journal of Psychological Research, 7(2), 64-75.

Roodbari, A., Ansari, S., Tavassoli, M. \& Nassaji, H. (2016). Antecedents of knowledge sharing: Trust, commitment and motivation. International Journal of Economics, Commerce and Management, IV(7), 52-63.

Stuhlman, D. D. (2012). Knowledge management terms. Retrieved from: http://home.earthlink.net/ ddstuhlman/defin1.

Suppiah, V. \& Sandhu, M. S. (2011). Organisational culture's influence on tacit knowledge sharing behaviour. Journal of Knowledge Management, 15(3), 462-477. DOI: 10.1108/13673271111137439.

Syed-Ikhsan, S. S. \& Rowland, F. (2004). Knowledge management in a public organization: a study on the relationship between organizational elements and the performance of knowledge transfer. Journal of Knowledge Management, 8(2), 95-111. DOI: 10.1108/13673270410529145.

Szulanski, G., Cappetta, R. \& Jensen, R. J. (2004). When and how trustworthiness matters: Knowledge transfer and the moderating effect of casual ambiguity. Organization Science, 15(5), 600-613.

Tsoukas, H. \& Vladimirou, E. (2001). What is organizational knowledge? Journal of Management Studies, 38(7), 973-993. DOI: https://doi. org/10.1111/1467-6486.00268.

Wiig, K. M. (1997). Knowledge management: Where did it come from and where will it go? Expert Systems with Applications, 13(1), 1-14. DOI: https://doi.org/10.1016/S0957-4174(97)00018-3.

Yang, S. \& Farn, C. (2006). An investigation of knowledge sharing from a social capital perspective: How social capital and growth needs affect tacit knowledge acquisition and individual satisfaction. Journal of Management, 23(4), 425-436.

Zaheer, A., McEvily, B. \& Perrone, V. (1998). Does trust matter? Exploring the effects of interorganizational and interpersonal trust on performance. Organization Science, 9(2), 141-159. DOI: 10.1287/orsc.9.2.141. 